\title{
UN TRÍPTICO EXPOSITOR EN LA EXPOSICIÓN ANGLO-LATINA DE LONDRES DE 1912
}

\author{
A TRIPTYCH DISPLAY FROM THE LATIN-BRITISH \\ EXHIBITION OF 1912 IN LONDON
}

Josep Capsir Maíz*

Museu del Disseny de Barcelona

\section{Resumen}

En pocas ocasiones continente y contenido pueden rivalizar en belleza y armonía como sucede con un tríptico expositor ejecutado en 1912 por la casa Esteva y Cía. de Barcelona, establecimiento especializado en la construcción de marcos y molduras, dirigido por Joan Esteva. Fue un encargo del dibujante industrial Mateu Culell. El mueble, de estilo modernista, debía servir de contenedor de los proyectos del artista catalán que viajarían a Londres, para estar presentes en la Exposición Anglo-Latina. Vemos, en este caso, una conexión evidente entre continente y contenido, exponentes del potencial creativo de una ciudad cosmopolita como Barcelona. Darlos a conocer, así como ofrecer una pincelada histórica sobre la empresa que construyó el mueble y el artífice de su contenido, situándolos en el contexto de la Exposición Anglo-Latina de Londres de 1912, es el principal objeto de nuestra comunicación.

Palabras clave: Exposición Anglo-Latina, Mateu Culell, Esteva y Cía., Modernismo

\section{Abstract}

Container and content rarely compete with each other in terms of beauty and harmony like they do in this triptych display made in 1912 by Esteva y Cía. of Barcelona, a company specialising in the construction of frames and trims, headed by Joan Esteva. It was commissioned by industrial designer Mateu Culell. This piece of Art Nouveau Style furniture was to be used as a container for the Catalan artist's projects, which would travel to London for the Latin-British Exhibition. There is an obvious link between container and content in this example, showing the creative potential of a cosmopolitan city like Barcelona. The main purpose of this message is to shed light on them, as well as to provide a historical perspective of the company that made the piece of furniture and the creator of its content, placing them within the context of the Latin-British Exhibition of 1912 in London.

Keywords: Latin-British Exhibition, Mateu Culell, Esteva y Cía., Art Nouveau 


\section{La Exposición Anglo-Latina de Londres de 1912}

Inaugurado el siglo XX, la ciudad de Londres utilizó una vez más la fórmula de proyectarse al mundo con la celebración de una serie de exposiciones de alcance internacional. Estas tendrían lugar en Shepherd's Bush, un espacio situado entonces en la periferia de la capital inglesa, cercano al Kensington Palace.

En este lugar se levantó la Great White City, un enorme recinto ferial expositivo provisto con numerosos pabellones y palacios de color blanco rodeados de generosos jardines. Allí tuvieron lugar la Franco-British Exhibition (1908); la Imperial Intenational Exhibition (1909), la Japan-British Exhibition (1910), la Latin-British Exhibition (1912), y la Anglo-American Exhibition (1914). Semanas después de la inauguración de esta última comenzaba la I Guerra Mundial.

\section{España y la Exposición Anglo-Latina}

En 1912 Londres, tenía proyectado presentar la Exposición Anglo-Latina de mayo a octubre, a la que serían llamadas a participar diversas potencias de ambos lados del Atlántico. A pesar de que España en aquellos años había perdido ya todas las colonias de ultramar sintió la necesidad de estar bien representada en el certamen ya que: "fue la primera a abrir al comercio las grandes vías del Atlántico, juntando de tal manera Europa con América”. ${ }^{1}$

Para estimular la participación de empresas en el evento la Cámara de Comercio de España en Londres, puso todo tipo de facilidades para que las artes, la agricultura, y la industria española estuvieran dignamente representadas. Para ello costeó a los expositores el espacio que necesitaran para mostrar sus productos, no así el embalaje y transporte que iría a cargo de cada uno de ellos. Trato a parte, y mucho más ventajoso, tendrían las obras pictóricas seleccionadas por el Ministerio de Instrucción Pública que viajarían a Londres para figurar en el Palacio de Bellas Artes.

La prensa de la época recogía el mensaje que lanzaba la Cámara de Comercio de España en Londres en su objetivo: "En su virtud y como quiera que al certamen concurren como exportadores, en unión de la Gran Bretaña, todos los pueblos latinos, incluso, por lo tanto, las repúblicas ibero-americanas, y concurrirán como visitantes millares y millares de viajeros, que de todas las partes de la tierra acuden en la primavera y el verano de todos los años a la gran metrópoli, es evidente que se ofrece a los productores españoles una oportunidad, más que excepcional única, para que con un gasto verdaderamente insignificante puedan dar a conocer sus artículos, no ya sólo a Inglaterra y a sus colonias, sino también al mundo entero en general y a las repúblicas centro y sud-americanas en particular". ${ }^{2}$

En Barcelona, una entidad como el Fomento de las Artes Decorativas, cuyos socios mayoritariamente ejercían una profesión relacionada con oficios artísticos y decorativos, más conocidos como bellos oficios y que defendía los intereses del colectivo, fue receptiva a la propuesta que llegaba de la Cámara de Comercio de España en Londres. Desde la entidad se elaboró una circular dirigida a todos ellos en la cual se les invitaba a participar en el certamen dada la calidad de sus productos y la ocasión de negocio que un evento de estas características pudiese comportarles. ${ }^{3}$ 
La inauguración, aunque anunciada para el 15 de mayo tuvo lugar el 25, y estuvo presidida por los Príncipes de Teck, Alejandro y su esposa Alicia. Se da la circunstancia que el primero era hermano de María de Teck, Reina consorte del Reino Unido, en aquellos momentos, por su matrimonio con Jorge V. En la ceremonia inaugural y en representación de España se pudo contar con la presencia de su embajador.

A grandes trazos en los ámbitos de la muestra se encontraban representadas Francia, Italia, España, Portugal, Latinoamérica, así como el Imperio Británico. La Official Guide afirmaba al respecto que: "The Latin-British Exhibition starts a new era, for it practically combine six Exhibitions in one, and embraces the arts, industries, life, and glories of France, Italy, Spain, Portugal, and Latin-America, as well as those of the Empire". ${ }^{4}$

Cabe significar que en el recinto ferial el Palacio de Bellas Artes, pabellón número 26, albergó de forma conjunta las muestras contemporáneas de arte británico, italiano, francés y español que se exhibieron en sus amplias galerías. Por lo que se refiere a España y gracias a la prensa de la época, conocemos los autores así como el título de las obras, seleccionadas y remitidas a instancias del Ministerio de Instrucción Pública, para estar presentes en este espacio expositivo. Fueron un total de 36 pintores, entre los cuales solamente había una mujer. Y cada uno de ellos presentaba una o dos obras. Podemos citar a modo de ejemplo Pedro Barragán, Paisajes de la Alhambra; Agapito Casas, Bosques de Camprodón; Constantino Gómez, Procesión en Albarracín; José Llanas, El sermón; Roberto Domingo Conducción de los toros; Luis Bertodano, Campiña del Guadalquivir; Alejandro Saint-Aubin, Campesina de Ávila; Eduardo Chicharro, Las tres esposas o bien a María Roësset, La Gitana. ${ }^{5}$ Por los autores y los títulos de las obras escogidos pensamos que con ellos se estaba transmitiendo al exterior, una imagen que potenciaba ciertos tópicos en buena medida muy arraigados en el imaginario colectivo. Tenemos noticias de que el galerista catalán Santiago Segura, de viaje por Europa, en aquellas fechas, visitó la Exposición Aglo-Latina. De sus manifestaciones a la prensa de la época se puede deducir que la elección de los pintores españoles representados en la muestra hubiera podido ser mucho más selecta y de mayor calidad. ${ }^{6}$

\section{Mateu Culell, proyectista industrial}

Creemos que el pabellón número 49, donde figuraba España, entre otros, acogía y exhibía las producciones agrícolas e industriales que llegaban procedentes de estas tierras (Fig.1). Gracias a un borrador de carta fechado en Barcelona el 23 de mayo de 1912 firmado por el proyectista industrial Mateu Culell Aznar (1879-1943), dirigido al Secretario de la Exposición, J. F. W. Hayns sabemos que sus trabajos estuvieron presentes en el certamen internacional de Londres. ${ }^{7}$ El dibujante, nacido en la capital catalana, de familia acomodada, tenía por entonces un taller ubicado en el número 42 de la Ronda de Sant Pere, en pleno Ensanche barcelonés. Mateu Culell era socio del Fomento de las Artes Decorativas y había formado parte de la Junta Directiva. ${ }^{8}$ Por tanto estaba bien informado sobre la presentación en Londres de la Exposición Anglo-Latina, 
circunstancia que aprovechó para presentar sus proyectos, tal y como había hecho en anteriores ocasiones, con reconocido éxito. ${ }^{9}$

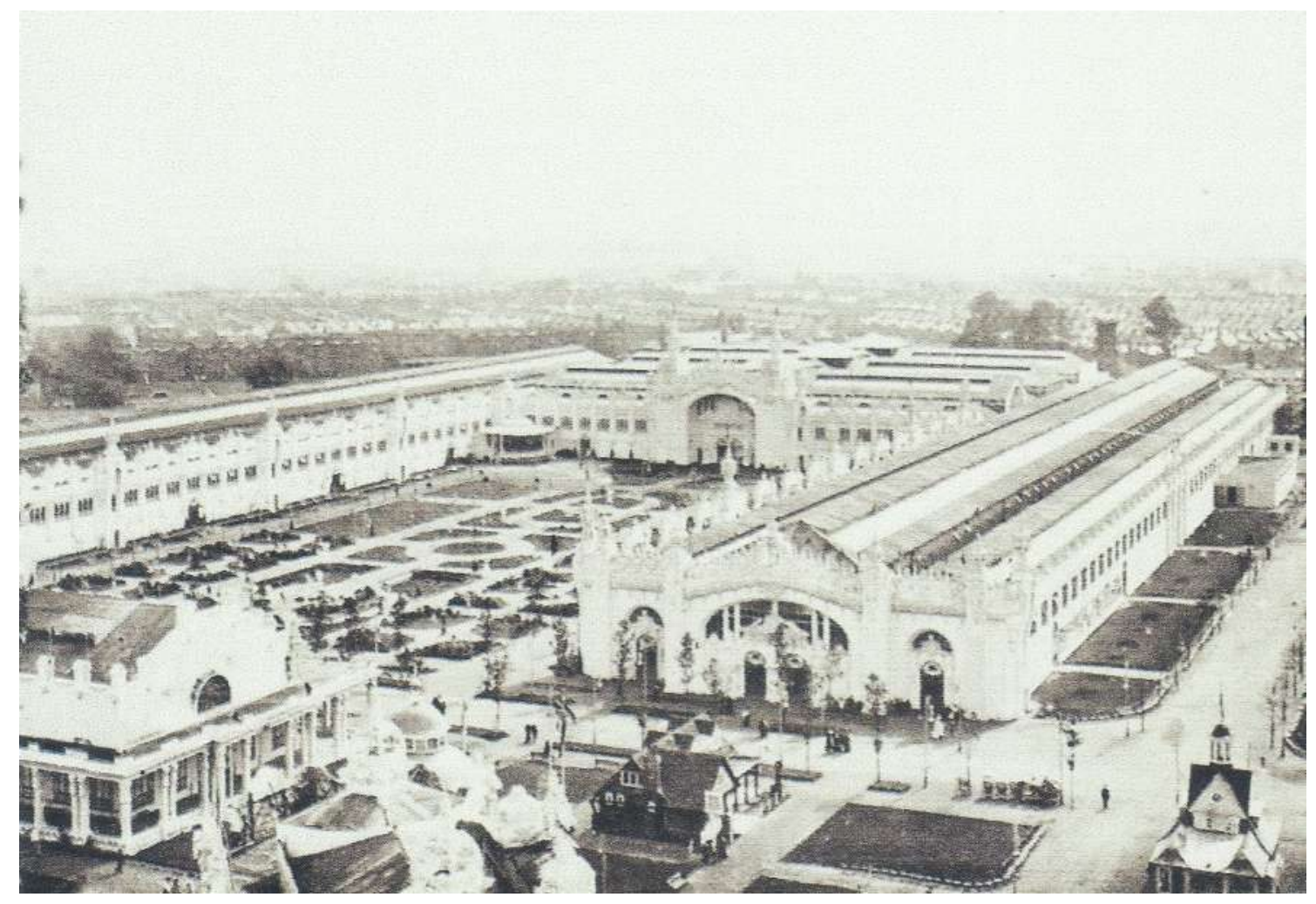

Fig. 1.El pabellón n ${ }^{\circ} 49$ del recinto ferial conocido como The Great White City situado en la periferia de Londres, acogía la Sección Española, en la Latin-British Exhibition de 1912.

Foto: Cuba en Europa.

\subsection{Los proyectos industriales de Mateu Culell en un tríptico expositor}

Mateu Culell comentaba en la carta postal el envío de su obra, cuya salida de Barcelona asegura que fue el 17 de mayo en el vapor Juno de la Compañía Mac Andrew. El coste del envío estaba pagado hasta Londres, así como su regreso a Barcelona, cuando terminase la muestra prevista para octubre del mismo año, en el caso de que su venta no fuese efectiva. Mateu Culell solicitaba noticias sobre la llegada del envío a su destino. Acompañaba a la carta un anexo con la misma fecha que esta, donde constaba la autoría, la dirección postal así como una breve descripción. Se trataba de: "dibujos para las artes decorativas o industrias artísticas. Un cuadro de madera en forma de tríptico con 3 cristales en cuyo interior hay una colección de dibujos originales pintados para las industrias artísticas de estampados, alfombras, mosaicos (con diferentes formas) cartas de tejido y joyas". ${ }^{10}$ Cabe añadir que esta descripción encaja con la distribución en que todavía a día de hoy se encuentran los proyectos en el interior del tríptico, haciendo una lectura de izquierda a derecha. El citado anexo relacionaba además las diferentes recompensas obtenidas en otras exposiciones, así como el 
año en que tuvieron lugar. Y otro dato importante el documento afirmaba que el cuadro, abierto, tenía como dimensiones 1'30 de alto x 1'45 de ancho. El precio de venta era de 2.000 pesetas.

En carta fechada en Londres el 12 de septiembre de 1912, C. R. Chisman, Secretario del Comité Ejecutivo de Bellas Artes de la exposición, comunicó a Mateu Culell que el cuadro se encontraba en aquel momento expuesto en la sección de Industria Española. ${ }^{11}$ Es el lugar que le correspondía ya que el dibujante proyectista con la exhibición de sus trabajos no pretendía otra cosa que darlos a conocer a los industriales y así aumentar la cartera de posibles clientes, tal y como ya lo había hecho en repetidas ocasiones, con notable éxito como ponen de manifestó los premios obtenidos a lo largo de su trayectoria (Fig.2). Y un hecho curioso que constatamos es que nunca antes, Mateu Culell había puesto tanto empeño en presentar sus proyectos de forma tan cuidada, en un tríptico expositor, ejecutado en la prestigiosa casa Esteva y Cía. de Barcelona, que por sí mismo ya podía considerarse una obra de arte. ${ }^{12}$ Una obra de arte que ponía de relieve el valor de su trabajo como dibujante proyectista. Aunque ello le supuso un enorme coste económico derivado de su traslado a Londres y el retorno a Barcelona, ya que la obra no llegó a venderse (Fig.3).

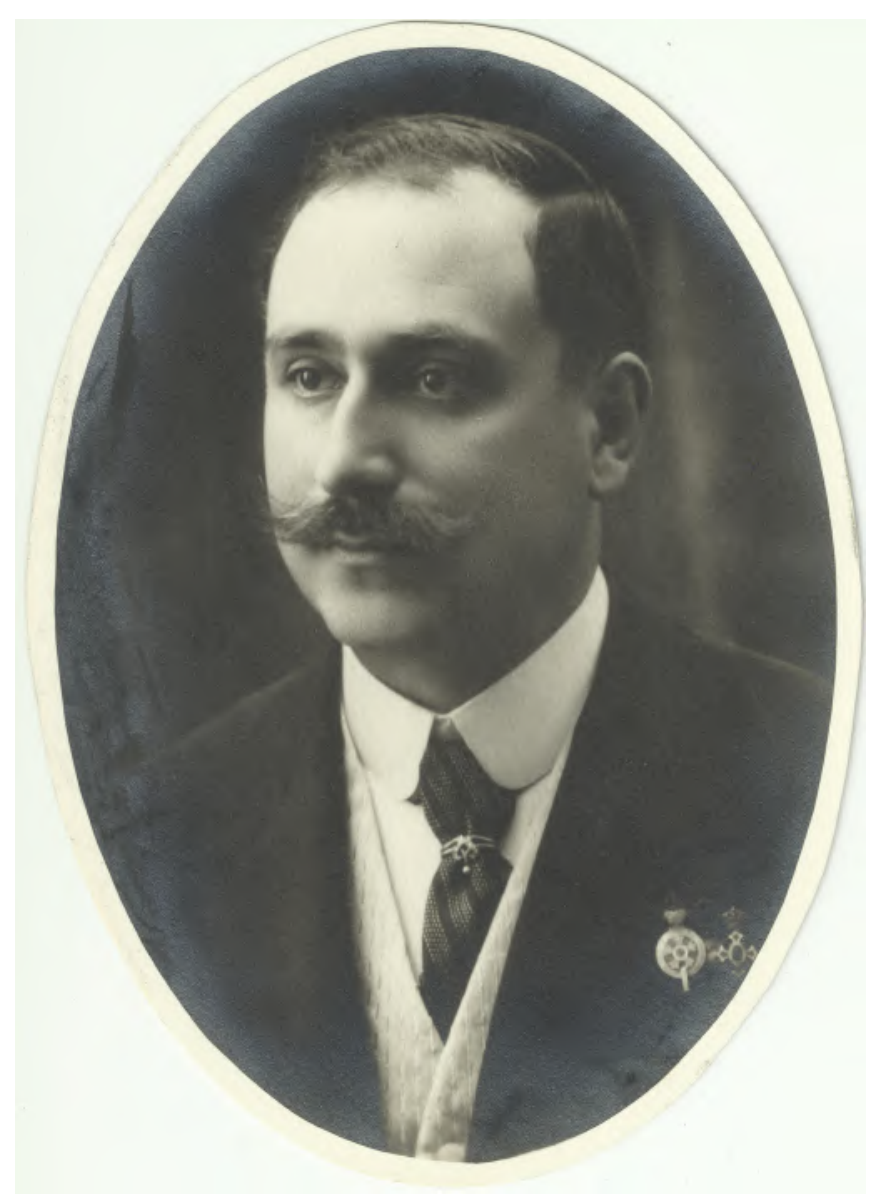

Fig. 2. Mateu Culell, exhibe en el pecho dos condecoraciones obtenidas en Londres en 1910 por su participación en la Exposición Internacional de Artes y Manufacturas. Museo del Diseño de Barcelona. 


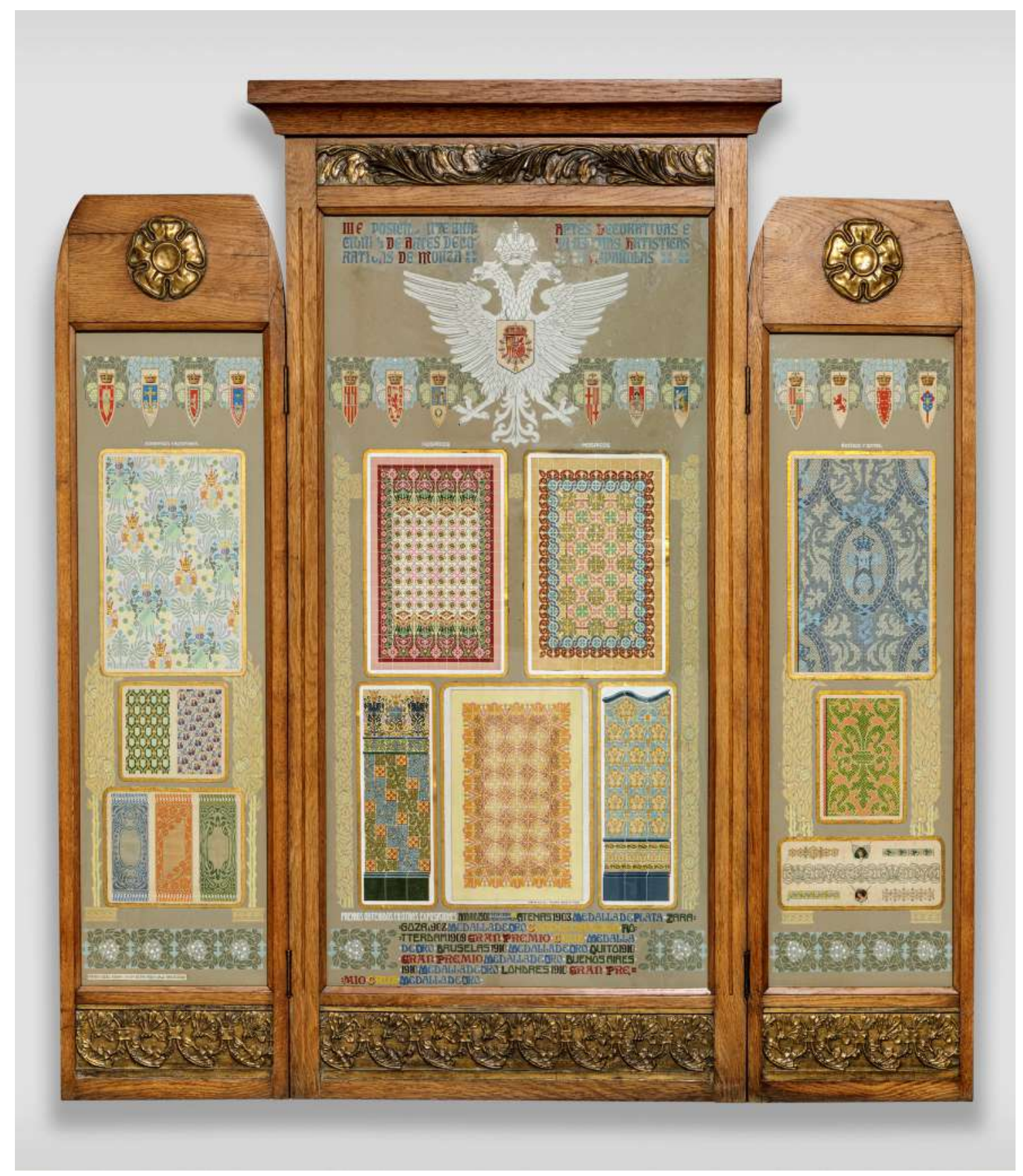

Fig. 3. Tríptico expositor construido por Esteva y Cía. de Barcelona, como contenedor de los proyectos decorativos de Mateu Culell, para ser exhibidos en la Exposición Anglo-Latina de Londres de 1912. Dimensiones: 129x125,5x6,5 cm. MADB 69.685. Museo del Diseño de Barcelona. Foto: Estudio Rafael Vargas.

\subsection{Contenido y descripción del tríptico expositor}

El tríptico muestra en cada una de las partes, un cartón base profusamente decorado con proyectos ejecutados con lápiz plomo y gouache sobre papel..$^{13}$ Iniciaremos la descripción por la parte central del tríptico, seguiremos a continuación por el lateral izquierdo y seguidamente el derecho. El cartón que se exhibe en el plafón central, es de mayor tamaño. En la parte superior aparece en letras pintadas la inscripción: "III EXPOSICIÓN INTERNACIONAL 
DE ARTES DECORATIVAS DE MONZA. ARTES DECORATIVAS E INDUSTRIAS ARTÍSTICAS ESPAÑOLAS”. Esta inscripción genera cierta controversia puesto que la muestra de Monza, a que hace referencia tuvo lugar en 1927, circunstancia que nos invita a pensar que fue añadida posteriormente. A continuación, se exhibe un águila bicéfala coronada, pintada directamente sobre el cartón. Pensamos que hace referencia a la dinastía de los Habsburgo, casa reinante en España desde 1516 hasta 1700, momento álgido de la colonización de América del Sur. Le sucedió entonces la dinastía de los Borbones cuyo escudo heráldico se encuentra superpuesto en la parte central del águila bicéfala. Casa reinante en España también durante buena parte del siglo XIX, momento en el que se produce la independencia de todos los países surgidos a partir de la colonización de América del Sur, y que ocupa la Jefatura del Estado todavía a día de hoy. Dicho escudo fue minuciosamente pintado en un papel, recortado y encolado sobre el cartón.

Junto a la parte inferior del águila bicéfala y a modo de cenefa aparecen los escudos de las ciudades de Valencia, Córdoba, Madrid, Barcelona, Sevilla y Badajoz. Ciudades de España que tuvieron todas ellas su réplica en diversos países del continente americano. Para la elaboración y colocación sobre el cartón de dichos escudos se utilizó el mismo método que en el escudo de los Borbones. Dichos escudos se encuentran colocados de forma equidistante y decorados por una envolvente y sugestiva ornamentación floral pintada directamente sobre el cartón, de inspiración claramente modernista.

A continuación, y bajo el enunciado de MOSAICOS se pueden visualizar dos dibujos de forma rectangular pintados, que son proyectos para pavimentos hidráulicos destinados a la decoración de suelos. El de la izquierda fue ejecutado sobre papel cuadriculado, pegado sobre un papel que exhibe en los extremos un marco dorado pintado. Este último se halla encolado al cartón base. El de la derecha fue realizado sobre papel pegado a otro papel que exhibe un marco dorado pintado. Este último se halla encolado al cartón base. En cuanto a los motivos ornamentales representados cabe destacar la viva policromía presente en ellos, así como la impronta modernista que exhiben con ciertas reminiscencias de carácter historicista.

Debajo de ellos hay tres modelos más, los de los extremos claramente son proyectos de arrimaderos cerámicos de pared y el central para pavimento hidráulico destinado a la decoración de suelos. En este último, en su parte inferior se puede leer la inscripción: MATEO CULELL AZNAR •BARCELONA•. En los tres casos se trata de un dibujo sobre papel pegado a otro papel que exhibe el borde dorado pintado. Este último encolado al cartón base. Se visualiza en ellos una decoración modernista que en algunos casos arrastra ciertos trazos de matiz historicista evidentes en la representación de elementos heráldicos como águilas y coronas. Los dos proyectos de los extremos son los únicos contenidos en el tríptico expositor que muestran un acabado brillante, quizás para imitar el aspecto del acabado de la cerámica.

La parte inferior del cartón tiene gran interés ya que en él se enuncian en una inscripción pintada, los principales premios obtenidos por Mateu Culell a lo largo de su trayectoria como dibujante proyectista, en otras exposiciones: "MADRID 1901, MENCIÓN HONORÍFICA; ATENAS 1903, MEDALLA DE 
PLATA; ZARAGOZA 1908, MEDALLA DE ORO, CONDECORACIÓN; ROTTERDAM 1909, GRAN PREMIO, CRUZ, MEDALLA DE ORO; BRUSELAS 1910, MEDALLA DE ORO; QUITO 1910, GRAN PREMIO, MEDALLA DE ORO; BUENOS AIRES 1910, MEDALLA DE ORO; LONDRES 1910, GRAN PREMIO, CRUZ, MEDALLA DE ORO" ${ }^{14}$ La inscripción se halla flanqueada por una cenefa floral de marcada inspiración modernista (Fig.4). ${ }^{15}$

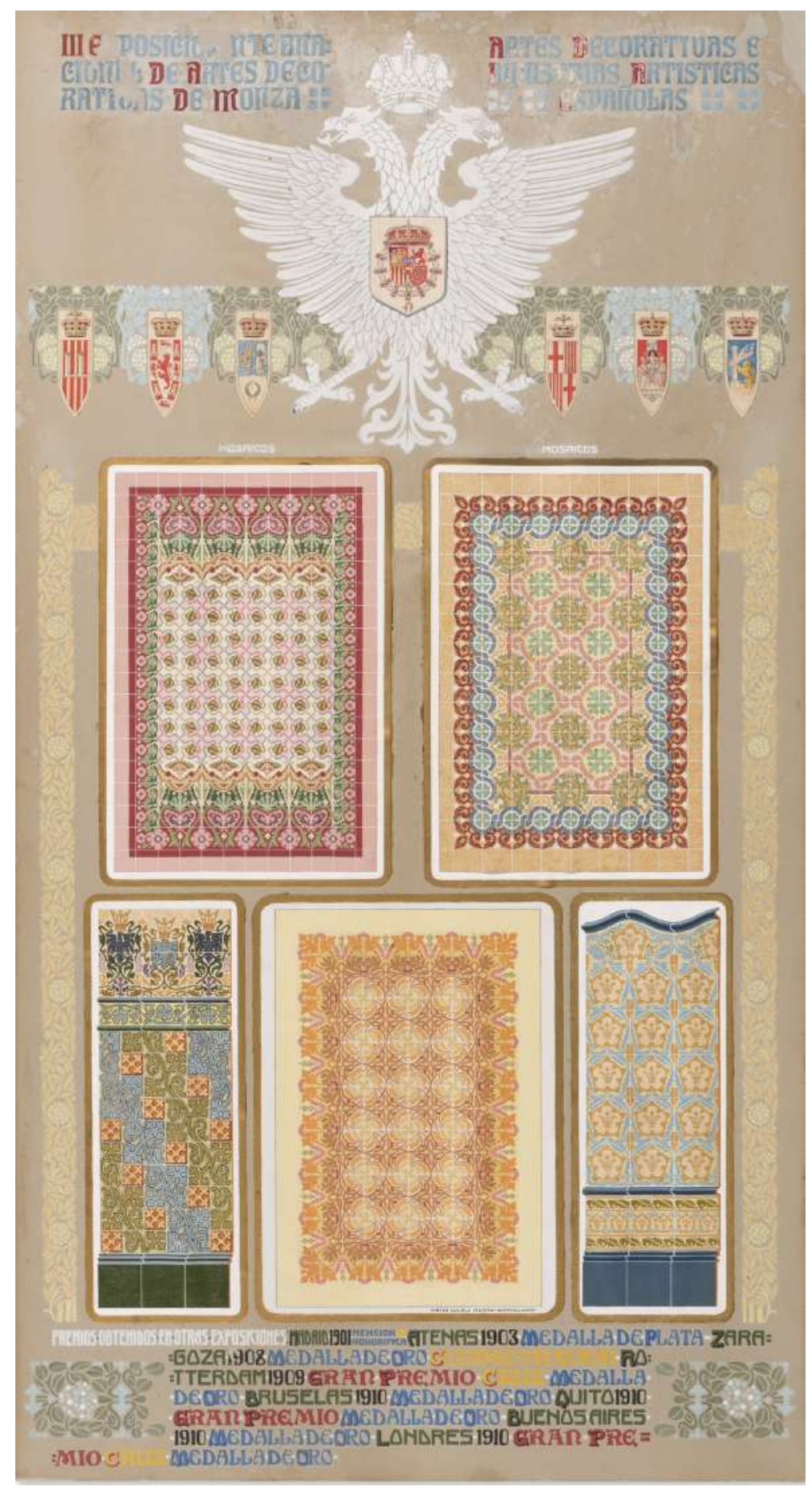

Fig. 4. Plafón central del tríptico expositor. Proyectos decorativos para mosaicos. Dimensiones: 100x53,5 cm. Foto: Xavi Padrós. 
En el plafón lateral izquierdo, siguiendo la misma línea decorativa que en los plafones central y derecho, el cartón base exhibe los escudos de las ciudades de Burgos, Oviedo, Zaragoza y Pamplona. Ciudades españolas que tienen todas ellas su réplica en el continente americano. Dichos escudos dibujados y pintados en papel, fueron recortados y encolados sobre el cartón. Se encuentran enmarcados por la misma cenefa ornamental pintada sobre él, que exhibe el cartón del plafón central y el derecho.

Bajo el enunciado de ESTAMPADOS Y ALFOMBRAS se visualiza en primer lugar un proyecto de forma rectangular. En él aparece como motivo decorativo principal un escudo heráldico en cuyo remate se muestra un yelmo y una corona detrás de los cuales se exhiben elementos ornamentales de carácter vegetal, entre los que identificamos la planta conocida como Monstera deliciosa, cuyo hábitat natural se encuentra en las selvas tropicales de América del Sur. ${ }^{16} \mathrm{El}$ proyecto está ejecutado sobre papel pegado a otro papel que exhibe un marco dorado y se encuentra este último encolado al cartón base. A continuación, podemos ver dos proyectos decorativos de forma rectangular decorados uno con motivos de malla y escudo y el otro con ornamentación floral los dos sobre un mismo papel que muestra un marco dorado. Dicho papel se encuentra pegado al cartón base. Estos tres proyectos fueron concebidos para la estampación de tejidos.

En la parte inferior se exhiben tres diseños de forma rectangular, decorados en azul, calabaza y verde respectivamente, ornamentados con motivos vegetales claramente modernistas. Estos tres diseños se encuentran elaborados sobre papel cuadriculado, recortado, y pegado sobre un papel en el cual se han añadido, coincidiendo con los dos extremos de cada proyecto, unos flecos pintados que ponen de relieve que se trata de propuestas ornamentales para alfombras. Todo el conjunto se encuentra encolado sobre un papel que exhibe un marco dorado y se halla pegado al cartón base. En la parte inferior se muestra una cenefa vegetal de marcada inspiración modernista, en consonancia con las que exhiben el plafón central y el izquierdo. A continuación, se muestra un papel encolado con la inscripción $\bullet$ MATEO CULELL AZNAR• RONDA DE SAN PEDRO, Nº $42 \bullet$ BARCELONA• (Fig.5).

En el plafón lateral derecho, siguiendo la misma línea decorativa que el plafón central e izquierdo, el cartón exhibe los escudos de las ciudades de Palma, León, Murcia y Santiago de Compostela. Se trata de ciudades españolas que tienen su réplica en el continente americano. Los escudos dibujados y pintados en papel fueron recortados y encolados sobre el cartón. Se encuentran enmarcados por la misma cenefa ornamental pintada sobre él, que exhibe el cartón del plafón central y el izquierdo.

Bajo el enunciado de TEJIDOS Y JOYAS podemos observar un proyecto para tejidos de forma rectangular, el cual exhibe un motivo decorativo con el monograma "A XIII" en cuyo remate aparece una corona real, clara referencia al monarca Alfonso XIII, circunscrito en un medallón, que evoca el estilo Luis XVI. Se encuentra ejecutado dicho proyecto sobre papel cuadriculado, pegado a otro papel que exhibe un marco dorado encolado al cartón base. Debajo de él se muestra otro proyecto para tejidos de forma rectangular, cuya figura central es un aro que sostiene una flor de lis, así como su réplica en sentido inverso. Todo ello sobre papel cuadriculado, pegado a otro papel que exhibe un marco dorado encolado al cartón base. 


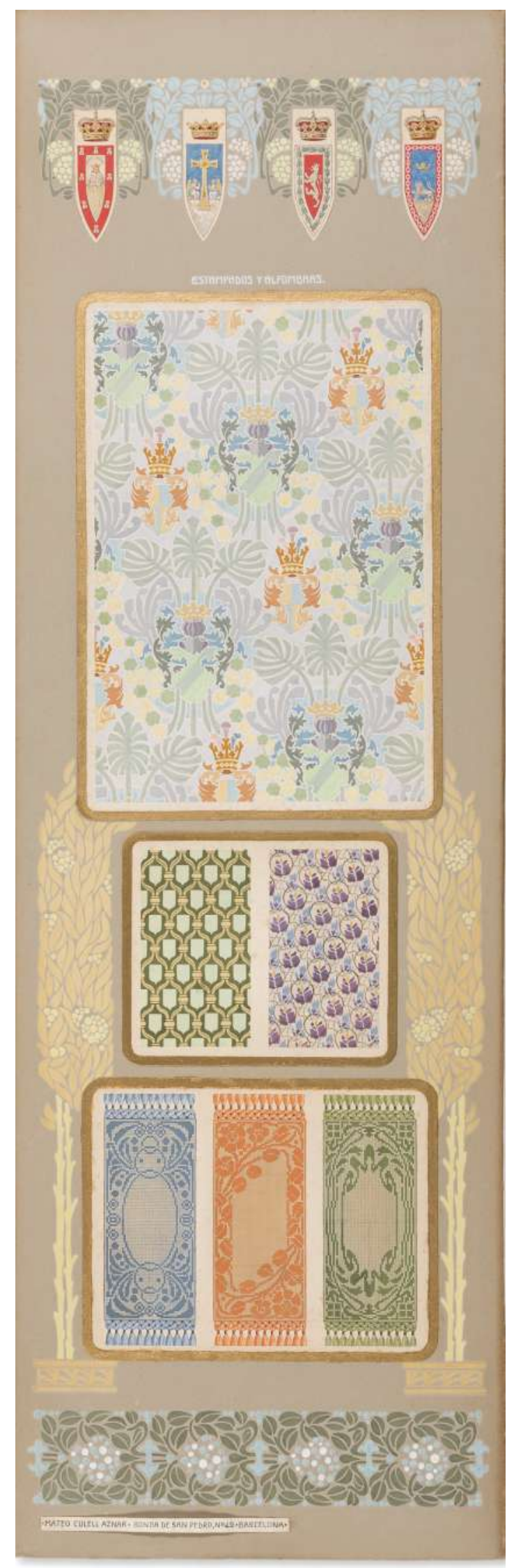

Fig. 5. Plafón lateral izquierdo del tríptico expositor. Proyectos decorativos para estampados y alfombras. Dimensiones: $85 \times 27$ cm. Foto: Xavi Padrós.

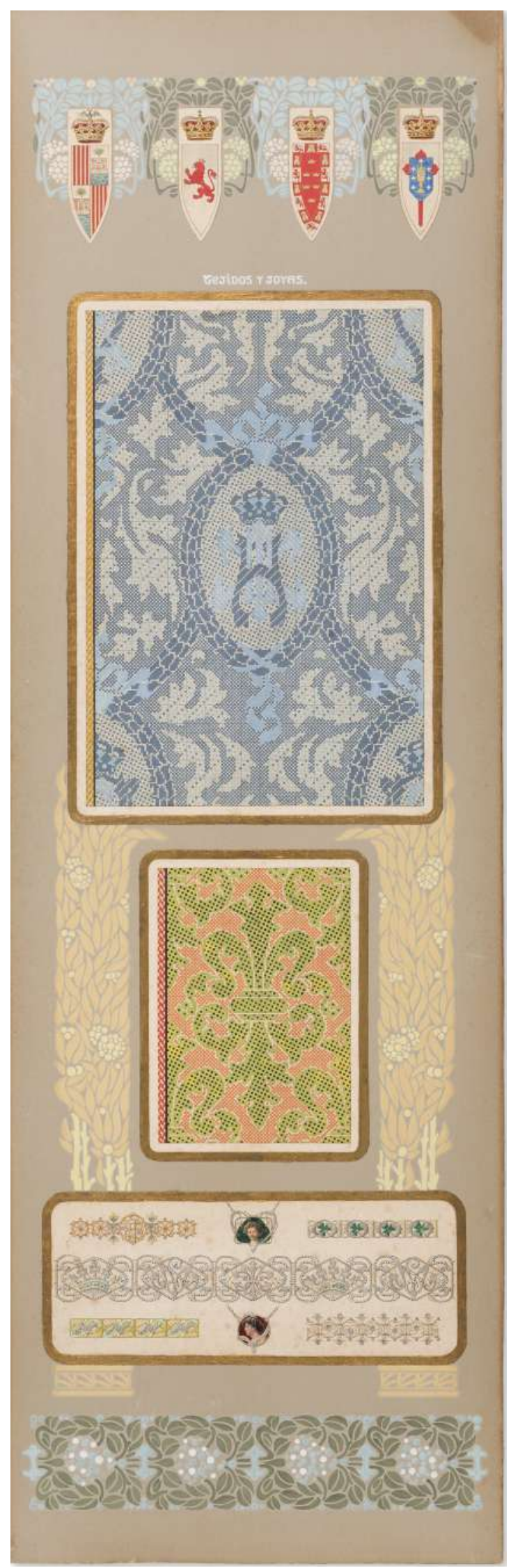

Fig. 6. Plafón lateral derecho del tríptico expositor. Proyectos decorativos para tejidos y joyas. Dimensiones: $85 \times 27 \mathrm{~cm}$. Foto: Xavi Padrós. 
La flor de lis, sin duda hace referencia a la dinastía de los Borbones, y en especial a Alfonso XIII, que reinaba en España en 1912, cuando tiene lugar la Exposición Anglo-Latina de Londres. A continuación, se visualiza una propuesta de proyectos de joyas, en concreto de pulseras y colgantes, con diseños que en algunos casos se acercan a una estética historicista y que en otros están más próximos al modernismo, ejecutados sobre papel pegado a otro papel que exhibe en sus extremos un marco dorado. En la parte inferior aparece pintada una cenefa floral de carácter modernista, en consonancia con el plafón central y el lateral (Fig.6).

En cuanto al tríptico expositor, fue un encargo de Mateu Culell a la casa Esteva y Cía. del barcelonés Paseo de Gracia, tal como indica una placa metálica en la parte posterior del marco central (Fig.7). La empresa entendió muy bien las necesidades del dibujante proyectista y diseñó el mueble en forma de tríptico expositor.

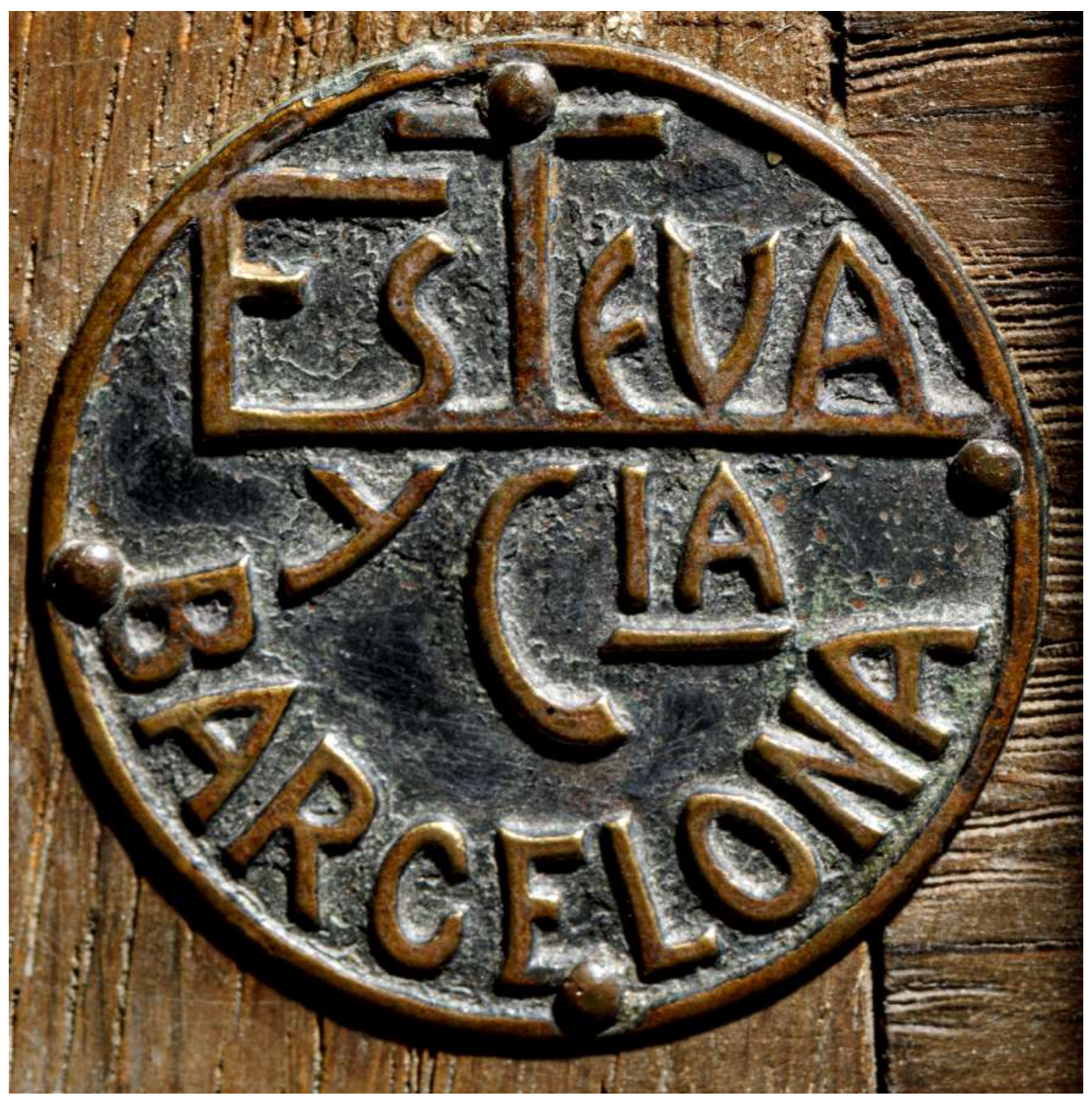

Fig. 7. Placa de metal identificativa de la casa Esteva y Cía., clavada en la parte posterior del marco central del tríptico expositor. Foto: Estudio Rafael Vargas. 
Se trata de un marco central de madera de roble, de forma rectangular, coronado por una elegante y sobria moldura. En la parte superior exhibe una cenefa vegetal de estuco dorado. La parte inferior muestra una cenefa de estuco dorado de carácter floral. Protege su interior un vidrio. Flanquean el marco central y sujetos por dos bisagras dos marcos de madera de roble, de forma rectangular y menor dimensión. Cada uno de ellos exhibe en la parte superior una roseta de estuco dorado y en la inferior la misma cenefa de estuco dorado con motivo floral que exhibe el marco central. Ambos marcos laterales protegen el interior con el correspondiente vidrio, se abren y cierran sobre el marco central, a modo de batientes, preservando su contenido y facilitando el transporte. ${ }^{17}$

La formulación del mueble en forma de tríptico permite que este al inclinar ligeramente los batientes laterales hacia delante tenga una gran estabilidad. Suficiente como para poder utilizarse de forma exenta reposando sobre una superficie plana a modo de expositor. Sin duda los proyectos decorativos industriales contenidos en su interior quedan realzados por la acertada formulación del mueble.

Mateu Culell, cuando cita el mueble en su conjunto, se refiere a él, en repetidas ocasiones como a un cuadro. Efectivamente el marco central del tríptico expositor, en la parte superior trasera, lleva incorporados dos elementos de sujeción, de hierro. Estos podrían utilizarse para anclar el conjunto en una pared. En este caso los trabajos de Mateu Culell se podrían exhibir efectivamente a modo de cuadro en formato tríptico. Circunstancia que evidencia todavía más la polivalencia y el acierto de este elegante mueble de clara inspiración modernista, acorde con el contenido del mismo. ${ }^{18}$

\section{Joan Esteva Casals: pintor, decorador y empresario}

A continuación, vamos a seguir la trayectoria empresarial de Joan Esteva Casals (1874 -1957), pintor y decorador vinculado a Barcelona, su ciudad natal, donde llevó a cabo numerosas iniciativas empresariales, sorteando a menudo infinidad de obstáculos. Nos vamos a centrar en el periodo que abarca de 1900 a 1936, cuando cosechó grandes éxitos, fruto de su incansable labor como decorador, de su talento profesional y también de sus habilidades como empresario. Recordemos que ya en tempranas fechas la prensa del momento se percataba del ingenio de Joan Esteva al afirmar que: "En Jaume Sans, acaba d'obrir en el carrer de la Boqueria, 32, un luxós establiment de camisería. Felicitem a don Joan Esteva, per l'exquisit gust en la direcció de dit decorat completament nou $y$ original". ${ }^{19}$ Nos vamos a ocupar de él en tanto que fue Esteva y Cía., bajo su dirección artística, la empresa que tal como hemos comentado anteriormente llevó a cabo la ejecución del original tríptico expositor para atender la petición del dibujante proyectista Mateu Culell, en 1912. ${ }^{20}$

\subsection{Hoyos, Esteva y C. ${ }^{\text {a }}$}

El 22 de junio de 1900 se constituyó en Barcelona la sociedad colectiva Hoyos Esteva y Compañía ${ }^{21}$. La integraban Claudio Hoyos Ayala (18751905), pintor, retratista así como ilustrador; Joan Esteva Casals, decorador 
y Francisco de Paula Figueras Sagués (1872-1948), pintor. Todos ellos tenían estrechos lazos con el Cercle Artístic de Sant Lluc, entidad de marcado talante católico, dedicada a la práctica y fomento de las artes. El objetivo de la sociedad constituida era la construcción y venta de objetos artísticos y decorativos. El capital social se estableció en 8.000 pesetas. Dos mil fueron aportadas por Claudio Hoyos, mil por Joan Esteva y cinco mil por Francisco de Paula Figueras. La gerencia quedó en manos de Claudio Hoyos y Joan Esteva. Este último llevaría sin duda la dirección artística. El negocio, estableció la razón social, el taller de producción así como el espacio dedicado a exposición y venta de sus artículos en el número 7 de la calle Paradís, en el casco antiguo de la ciudad.

Hoyos, Esteva y C. ${ }^{\text {, }}$, debió prosperar pronto, ya que tenemos noticias que en 1901 el negocio se trasladó a un lugar más céntrico, al número 4 de la calle Cardenal Casañas. ${ }^{22}$ Es significativo constatar la buena reputación que adquirió la empresa tal como se puede observar en las afirmaciones que recogía la prensa de la época: "Hallase expuesto en el establecimiento de los señores Hoyos, Esteva y Compañía un magnífico mobiliario para dormitorio, digno de llamar la atención por su riqueza y buen gusto.

La cama, de olivo y caoba, está adornada con incrustaciones de madera pirograbada representando a San Jorge, y recuerda, dentro del modern style, la noble severidad de líneas y la solidez de resistencias características del arte catalán. El armario de luna, de iguales materiales, es asimismo suntuoso, demostrando el partido inapreciable que se puede sacar del olivo, por su hermosísimo jaspeado, en el arte del mueble.

Lo mismo la cama que el armario se recomiendan por el acabado esmero con que están atendidos todos los accesorios, como así es del caso tratándose de obras que pretendan ostentar un sello verdaderamente artístico, y no confundirse con un trabajo puramente industrial". ${ }^{23}$

Sabemos que la empresa se dedicaba a la decoración completa de interiores, con la inclusión de bustos, columnas, relojes, espejos, molduras, marcos, lámparas, así como imágenes religiosas y ornamentos propios para el culto. También se ofrecían reproducciones o bien reconstrucciones de muebles antiguos. Por si ello no fuera poco también se ejecutaban proyectos a petición del comprador, desarrollando cualquier idea en el campo del arte decorativo. ${ }^{24}$

\subsection{Esteva, Figueras y Sucesores de Hoyos}

El 3 de abril de 1905 falleció de forma repentina Claudio Hoyos Ayala. La sociedad continuó entre los socios restantes, es decir Joan Esteva Casals y Francisco de Paula Figueras Sagués. En sustitución del difunto se añadió su viuda Concepción Doménech Vendrell, con la que había contraído nupcias en 1899, en tanto que usufructuaria y representante de sus hijos Claudio, José, Ignacio y Montserrat Hoyos Doménech, sucesores del fallecido padre y menores de edad. La gerencia quedaría en manos de Joan Esteva y Francisco de Paula Figueras. ${ }^{25}$

Tenemos noticias de que el 18 de julio de 1905 los tres socios compraron un solar edificable de $1.209 \mathrm{~m} 2$ en el número 112 de la calle Universidad, en pleno Ensanche barcelonés con el objetivo de poder construir en él el taller y el almacén de la empresa. ${ }^{26}$ Por dicha circunstancia pidieron un préstamo 
con garantía hipotecaria sobre la finca de 65.000 pesetas a Joaquin Figueras Barrulls, a devolver en cinco años. ${ }^{27}$

En cuanto al espacio de exhibición y ventas sabemos que en aquellas fechas el negocio se había trasladado a la calle de Santa Ana y continuaba gozando del mismo prestigio de siempre. Abundaban en sus estancias objetos decorativos de gusto exquisito y se presentaban a menudo exposiciones que daban protagonismo a diversos pintores. Valga a modo de ejemplo el caso de Antonio Utrillo. La prensa de la época afirmaba que: "Resulta grandioso el éxito de la exposición de originales debidos a Antonio Utrillo, por las numerosas adquisiciones que se hacen de los mismos. Estos, colocados en marcos de una gran riqueza de gusto artístico, son, como es natural, fabricados por la casa que los expone, Esteva, Figueras y Sucesores de Hoyos, calle de Santa Ana, número 6". ${ }^{28}$

En mayo de 1906 contrajeron matrimonio Alfonso XIII y Victoria Eugenia, un acontecimiento de vital importancia en la vida social de España. Para la ocasión el pintor e ilustrador Joaquin Diéguez realizó una oleografía sobre cartulina a todo color de los jóvenes reyes que se estampó en los talleres gráficos Garcés y Bartolí de Barcelona. Dicha obra estaba destinada a figurar en despachos de corporaciones públicas así como de entidades privadas.

Es significativo que la revista educativa El Magisterio Español editada en Madrid, e impulsora del proyecto, y en cuya razón social se podía adquirir la obra anunciase en sus páginas que: "para el mayor lucimiento de la oleografía la reputada casa de «Esteva, Figueras y Sucesores de Hoyos», de Barcelona, ha confeccionado ex profeso, grandiosos y artísticos marcos, de insuperable gusto y riqueza", ${ }^{29}$

La madrugada del 29 de agosto de 1907, el taller, así como los almacenes de la sociedad, ubicados en el número 112 de la calle Universidad sufrieron un aparatoso incendio, y tal como describe la prensa de la época: "Fuerzas de la guardia municipal y orden público, dedicábanse a desalojar la parte del local que todavía respetaban las llamas, consiguiendo poner a salvo varios muebles de no escaso valor, sin tener en cuenta el peligro que con ello se corría pues volaban impulsados por la fuerza de las llamas gruesos tizones que caían a distancia.

Al cabo de una hora de iniciado el siniestro, una densísima y negra columna de humo, así como un ensordecedor estrépito, anunciaron que acababa de desplomarse el techo del edificio y al enorme boquete dirigiéronse entonces todas las mangas, consiguiéndose a las dos de la madrugada que quedara localizado por completo el fuego". ${ }^{30}$ A pesar del descalabro económico que supuso el incendio, la empresa pudo continuar con su actividad con normalidad, en el establecimiento de ventas que permanecía en el número 6 de la calle Santa Ana.

\subsection{Esteva y Cía.}

El 20 de enero de 1908 Francisco de Paula Figueras, quedó apartado de la sociedad recibiendo su correspondiente participación. También quedaron separados de la misma, recibiendo la remuneración que les correspondía los hermanos, menores de edad, Claudio, José, Ignacio y Montserrat Hoyos Doménech. La sociedad continuó con Joan Esteva Casals, como gerente y Concepción 
Doménech, su futura esposa, bajo la razón de Esteva y Compañía. ${ }^{31}$ La empresa será identificada a partir de ahora con un logo diseñado por el ilustrador Josep Triadó que exhibía un caballo alado (Fig.8). ${ }^{32}$ De acuerdo con Antonio Navarrete Orcera se trata de Pegaso, montado por una figura femenina que porta una rama de olivo en la mano, que podría ser una alegoría de la Paz. ${ }^{33}$ Encima de la cabeza de Pegaso se vislumbra una pequeña figura femenina con alas, que representa a la Fama o la Victoria que sin duda puede vincularse con la inscripción latina de ARS que aparece en la izquierda de la imagen. Todo parece invitarnos a pensar en la calidad y belleza de los productos salidos de los talleres de Esteva y Cía., que podrían considerarse preciadas obras de arte. El establecimiento comercial vivirá además en estos momentos una época de prosperidad como pone en evidencia su traslado en otoño de 1911 al número 18 del prestigioso Paseo de Gracia, con esquina en la Gran Vía. Se da la circunstancia de que dicho establecimiento fue distinguido en el Concurso Anual de Edificios y Establecimientos Urbanos promovido por el Ayuntamiento de Barcelona, al considerar el jurado que este, junto a otros cuatro, abiertos en aquel mismo año, eran merecedores del premio extraordinario consistente en una placa decorativa de bronce, en la cual constaba el premio obtenido, y que debía lucir en la fachada del edificio (Fig.9). La noticia fue recogida ampliamente en la prensa de la época y sirvió para prestigiar al ya de por sí renombrado negocio dirigido por Joan Esteva, autor del proyecto decorativo de su flamante establecimiento comercial ${ }^{34}$ Cabe decir que la materialización del premio no tuvo lugar hasta el 23 de junio de 1913 (Fig. 10). Ese día el entonces alcalde accidental de Barcelona José Antonio Mir Miró hizo entrega, de la citada placa de bronce a Joan Esteva y Concepción Doménech, con la que ya había contraído matrimonio, ambos en aquellos momentos únicos propietarios del negocio. Los acompañaban en el acto, otros miembros del consistorio barcelonés, así como el secretario del concurso, Carlos Pirozzini Martí. La noticia tuvo gran difusión en la prensa de Barcelona. ${ }^{35}$

Como dato anecdótico pero de cierto interés cabe decir que en diciembre de 1913 se presentó en el espacio habilitado para exposiciones del establecimiento comercial de Joan Esteva, una muestra de trabajos de las alumnas del maestro Ricardo Martí, que regentaba una academia artística. Se trata básicamente de pinturas, realizadas todas ellas por mujeres y de la que excepcionalmente disponemos de alguna imagen que nos permite visualizar la exposición, así como la sala que la acogió en Esteva y Cía, (Fig.11). ${ }^{36}$

Durante los años que siguieron el negocio de venta de marcos, molduras y objetos artísticos, continuó subsistiendo acompañado de la presentación de exposiciones en el establecimiento comercial. Se trataba de obras de artistas como Julio Armengol, Rafael Segura, Francisco Gallofre, Antonio de Ferrater, Eugenio Hermoso y Adelardo Covarsi la mayoría pintores catalanes y españoles en general, de discreta proyección pública. A partir de 1915 la empresa exhibirá un nuevo logo diseñado por el ilustrador Joan Junceda, mucho más explícito y comercial que el anterior. 


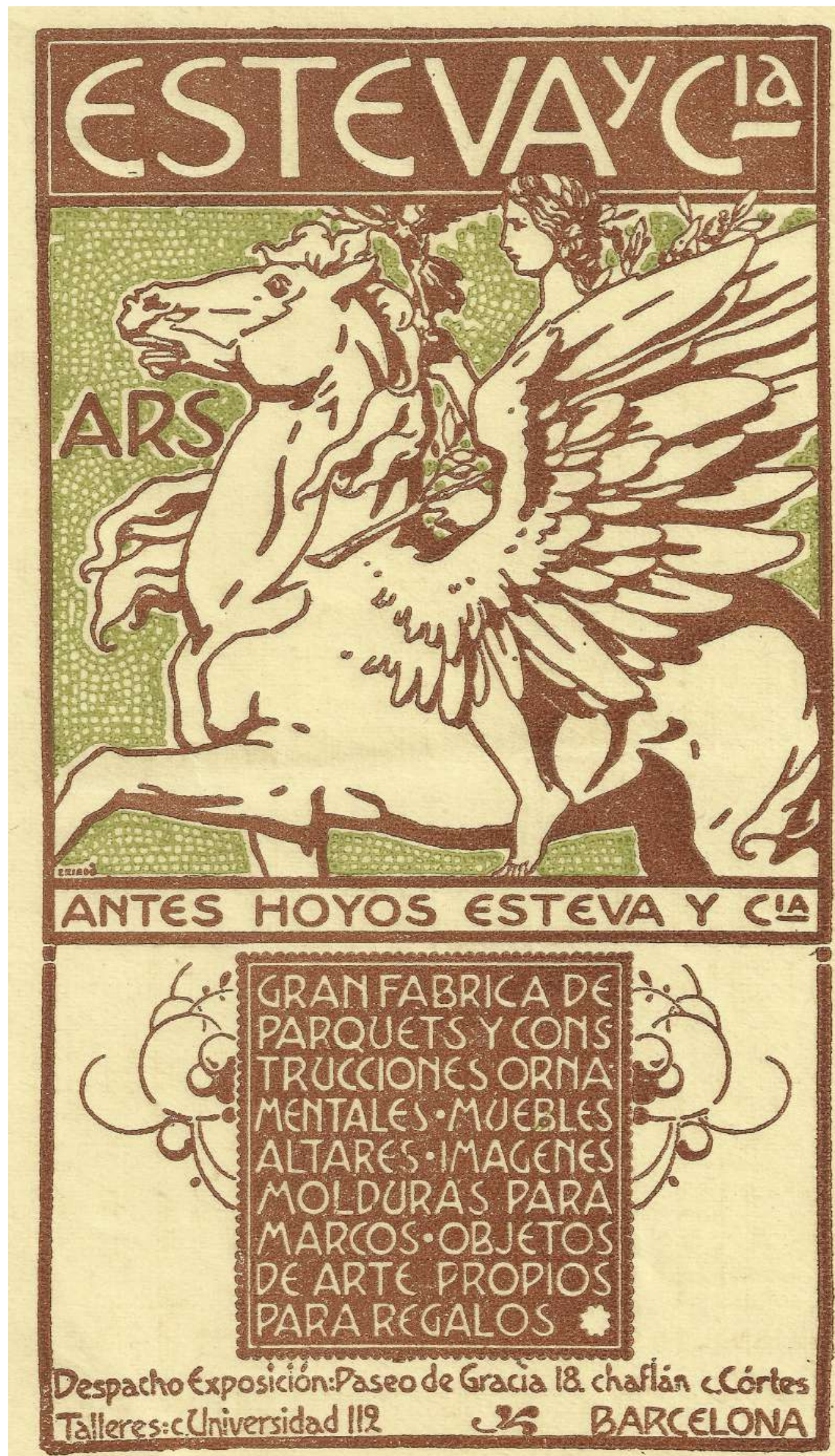

Fig. 8. Anuncio publicitario con el logo de Esteva y Cía. Diseño de Josep Triadó, 1912. 


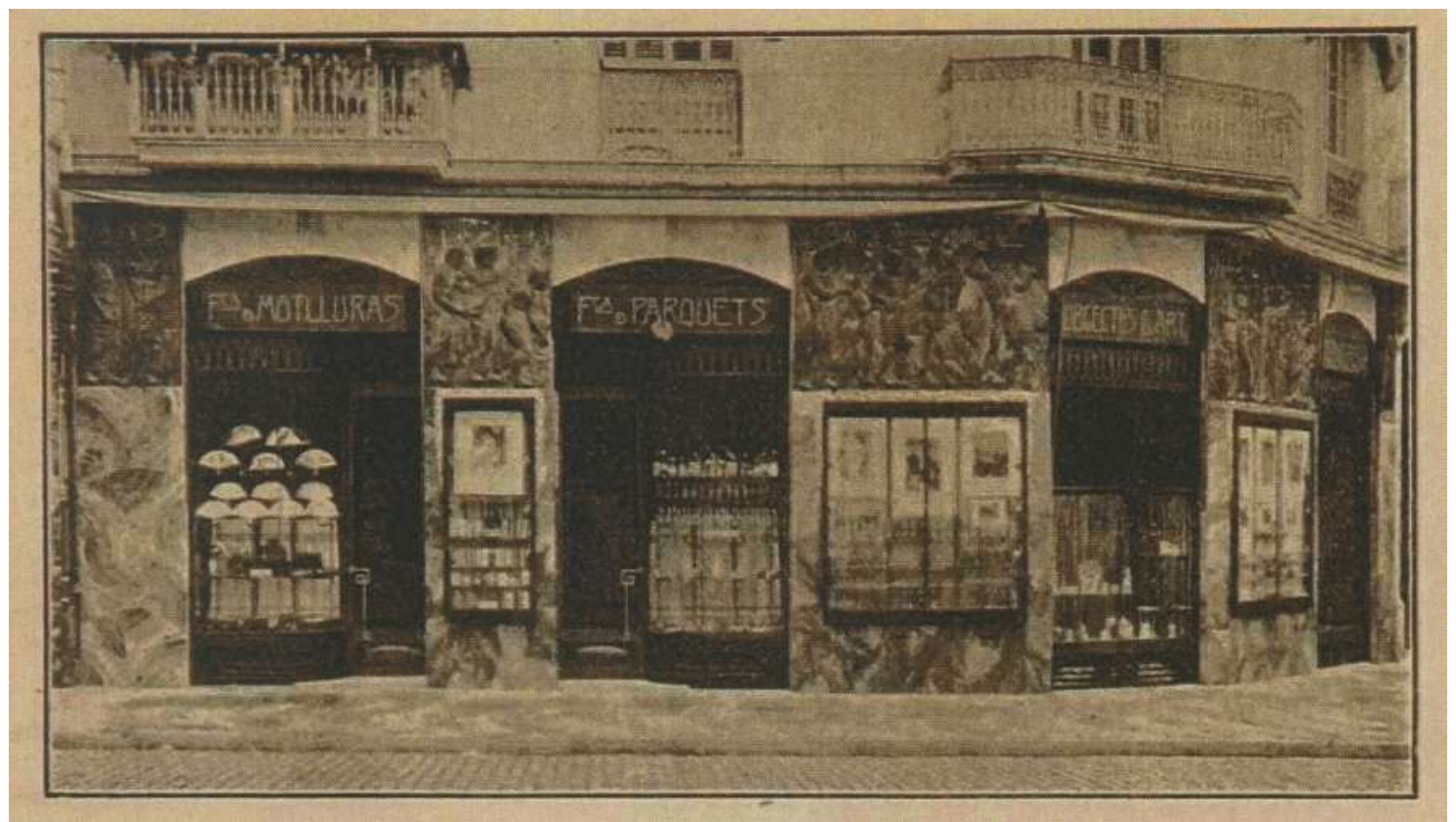

Fig. 9. Fachada de Esteva y Cía., en el Paseo de Gracia $n^{\circ} 18$, cuyo proyecto decorativo obtuvo un premio extraordinario en el Concurso Anual de Edificios y Establecimientos Urbanos del Ayuntamiento de Barcelona, en la edición de 1911. Foto: Anuario Estadístico Ciudad de Barcelona.

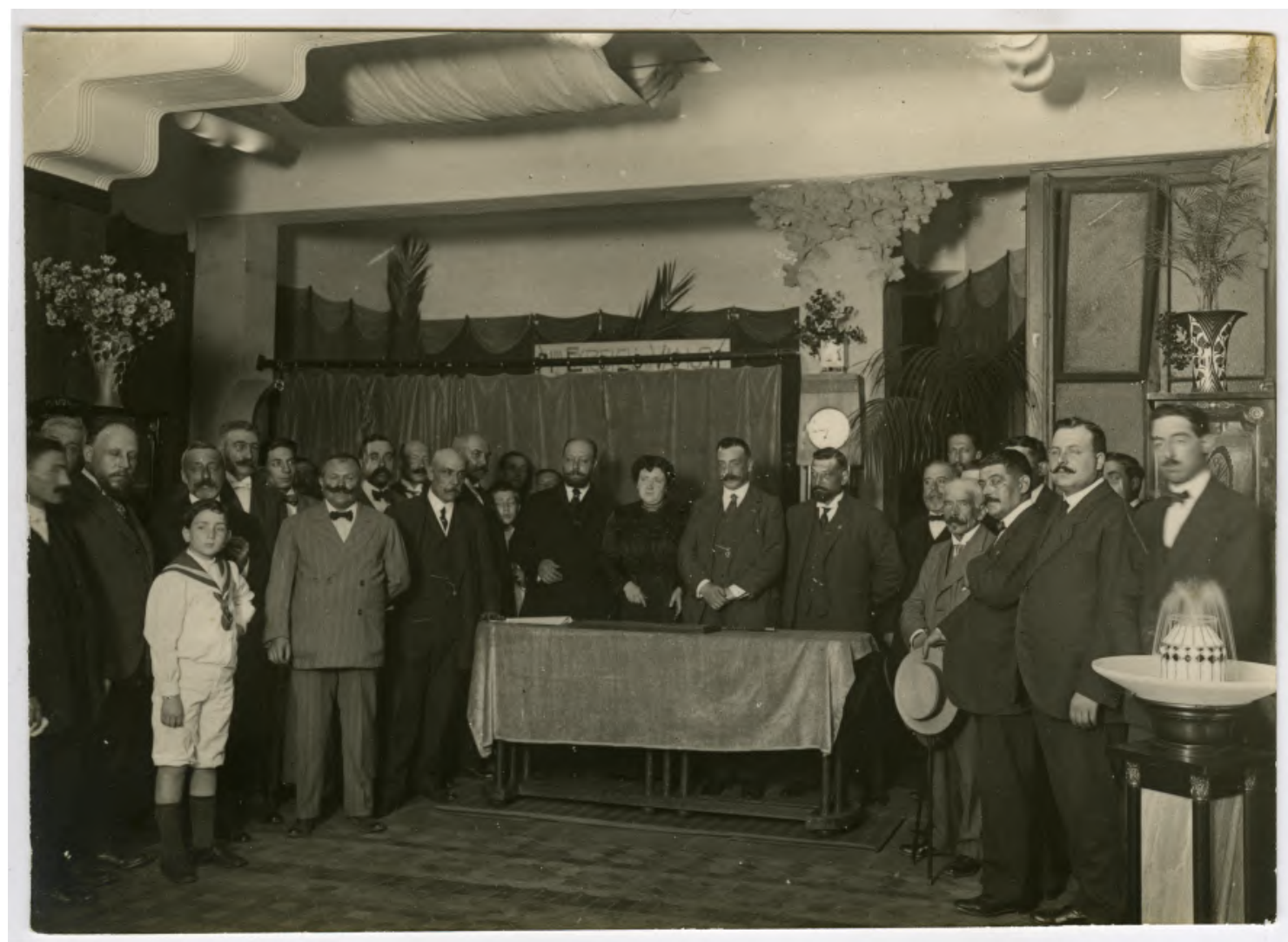

Fig. 10. El 23 de junio de 1913 el alcalde de Barcelona José Antonio Mir hizo entrega a Joan Esteva y su esposa Concepción Doménech, en el interior de su establecimiento del Paseo de Gracia, la placa que acreditaba el premio obtenido en 1911. Foto: Archivo Fotográfico de Barcelona. 


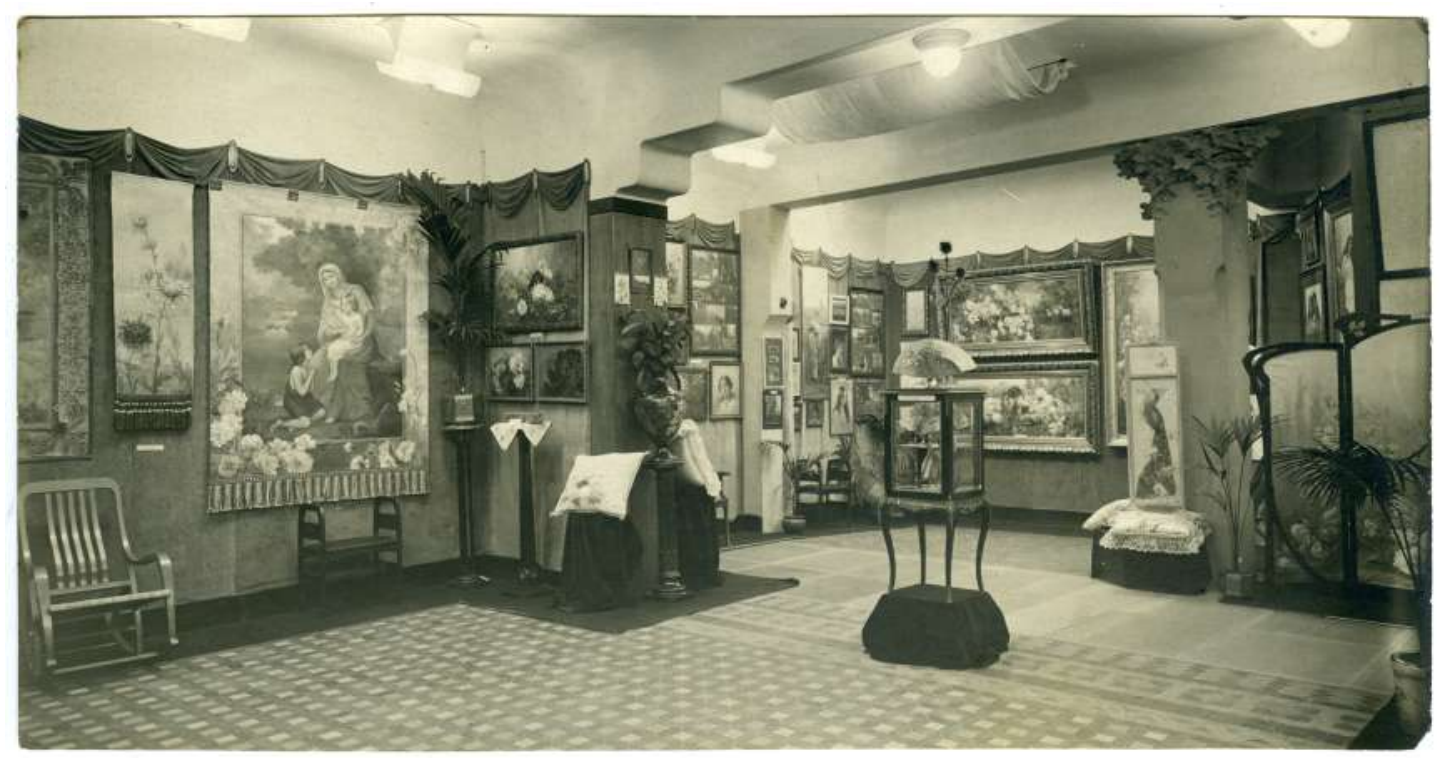

Fig. 11. Espacios expositivos de la casa Esteva y Cía., en diciembre de 1913, cuando se exhibía una muestra de trabajos de las alumnas del maestro Ricardo Martí.

Foto: Archivo Fotográfico de Barcelona.

\subsection{Esteva y Cía. S. en C.}

El 5 de agosto de 1921 Joan Esteva y Concepción Doménech, admiten en la sociedad a Fausto Ortega Descárrega y a Miguel Castellví Catalá transformándola en comanditaria tal y como quedará reflejado en anuncios publicitarios que aparecerán en la prensa a partir de ese momento. ${ }^{37}$ Ello comportará un aumento del capital social de la empresa. El fallecimiento de Miguel Castellví Catalá el 1 de mayo de 1922 ocasionará nuevos cambios en la sociedad. Le sustituirá su viuda Asunción Gutiérrez Salete y a la vez ingresará como socio en la misma, Claudio Hoyos Doménech.

En 1923 Barcelona será escenario de la Exposición Internacional del Mueble y decoración de Interiores. Esteva y Cía. S. en C. estará presente en el certamen con un stand de planta cuadrada simulando un templete ornamentado con elementos decorativos inspirados en la Grecia clásica. Escenario apropiado para exponer una muestra representativa de marcos y molduras, especialidad de la casa. En aquella época en Barcelona, el Noucentisme, movimiento cultural de raíz mediterránea, había desplazado definitivamente al Modernismo. La empresa obtuvo una medalla de honor como reconocimiento a sus elaborados productos. ${ }^{38}$

A finales de 1926 abandonarán la sociedad, Fausto Ortega Descárrega, Asunción Gutiérrez Salete y Claudio Hoyos Doménech, recibiendo su correspondiente participación. La sociedad continuará con los dos únicos socios, el matrimonio Joan Esteva y Asunción Doménech que ostentaran la gerencia de la empresa que recuperará de nuevo el nombre de Esteva y Cía., y con él estará en funcionamiento hasta finales de 1929.

En esta época cabe destacar los trabajos que la empresa llevó a cabo en la Iglesia parroquial de Santa María del Mar, recién concedido al templo en 1923 
el título de basílica. Su complejidad pone en evidencia la capacidad de trabajo del taller, en el que no había límites en cuanto a la utilización de materiales y técnicas utilizados para llevar a cabo sus creaciones tal como recoge la prensa del momento: "Ha proyectado y dirigido nuestro ilustre colaborador, el arquitecto don Buenaventura Bassegoda las insignias basilicales para el expresado templo, las cuales pueden ser admiradas en la casa Esteva, a cargo de la cual corrió ejecutarlas.

Una de ellas es el «tintinabulum», de madera de cedro con dorados mates y tonos que con estos conjugan delicadamente, formando el conjunto la reproducción de los dos campanarios de la mentada iglesia, los que flanquean elementos inspirados en la fachada de ésta, pendiente del arco apuntado la campanilla de bronce plateado y ostentando, en uno de los lados, el escudo de la parroquia y en el otro una transcripción escultórica de la Ascensión de la Virgen, de Gurri, que figura en el altar mayor de la iglesia de Santa María del Mar.

La otra insignia es el "paviglione», en la cual utilizáronse damascos de seda roja y amarilla, alternados, y con idéntico motivo decorativo, apareciendo en la parte pendiente, bordados al realce, los escudos de Santa María del Mar, el Pontificio y el Episcopal, figurando en el ápice la cifra de María y ofreciendo el conjunto, de acertadas proporciones, gran impresión de suntuosidad.

Ambas insignias constituyen, por su concepción y el acierto en la combinación de los materiales, sendas obras de arte suntuario litúrgico de inapreciable estima". ${ }^{39}$

También tenemos noticia que en 1926 Esteva y Cía. S. en C. había suministrado marcos de madera para la nueva decoración del antiguo boudoir de la reina Victoria Eugenia, en el barcelonés Palacio de Pedralbes. Este espacio de forma circular, junto al dormitorio de la soberana, decorado originalmente por Santiago Marco en estilo Art Déco se había transformado aquella primavera en salita de estar. ${ }^{40}$ Esteva y Cía. S. en C. también suministró una mesita costurero, que creemos puede ser la misma que en el año 2011 se exhibía en el dormitorio de la reina Victoria Eugenia. ${ }^{41}$ En este caso se trata de una mesita costurero de color marfil, de estilo Luis XVI, sustentada por tres patas, y cuyo tablero de forma circular se encontraba decorado con una pintura de carácter figurativo cuyas protagonistas eran tres mujeres. ${ }^{42}$ El faldón exhibía delicadas guirnaldas doradas. ${ }^{43}$

Sabemos además que en aquellas fechas, cuando se llevó a cabo la decoración de la salita de estar de la Reina en el Palacio de Pedralbes, el taller de fabricación de la empresa se había trasladado al número 2 de la calle Sagrera, aunque el despacho de venta continuaba en el número 18 del Paseo de Gracia, pero por poco tiempo.

\subsection{Casa Esteva, S.A.}

En 1929 Joan Esteva Casals y su esposa Concepción Doménench Vendrell en unión a Emilio Baseda García, transforman la sociedad Esteva y Cía. en anónima, que actuará bajo la denominación de Casa Esteva, S.A. acordando que el objeto de la misma será la de siempre, es decir la fabricación y venta de 
muebles, marcos, molduras y toda clase de objetos artísticos y decorativos, continuando la fabricación, así como la razón social al número 2 de la calle Sagrera. Un emplazamiento alejado del centro de la ciudad, que sin duda abarataría costes de producción. El espacio de venta se situaría en el número 12 de la calle Gravina, una discreta calle del Ensanche barcelonés. El capital social de un millón cinco mil pesetas fue suscrito inicialmente por Joan Esteva, Concepción Doménech y Emilio Baseda. El Presidente del Consejo de Administración de la nueva sociedad sería Joan Esteva. El Secretario Octavio Doménech Vendrell. Los Vocales Concepción Doménech, José Hoyos Doménech, Ignacio Hoyos Domenech, y Octavio Domenech Vendrell. Fueron nombrados gerentes de la sociedad Concepción Doménech y José Hoyos Doménech. Hacia 1934 el taller de fabricación, así como el espacio de venta se concentraron en el número 21 de la calle Caspe, un lugar céntrico en el corazón del Ensanche barcelonés. En 1935 se inauguró en el mismo emplazamiento la Sala Esteva, que funcionaría como galería de arte. Del 13 al 30 de enero de 1936 esta acogió una célebre exposición de Pablo Picasso integrada por 25 obras que exhibieron la vertiente más vanguardista del genio malagueño.

Existe la falsa creencia de que con la Sala Esteva, se extinguió la actividad comercial que había caracterizado el negocio de Joan Esteva desde sus orígenes. Como empresa dedicada a la fabricación y venta de marcos, molduras y objetos artísticos. Nada más lejos de la realidad, como pone en evidencia la noticia aparecida en la prensa de la época en relación con el Carnaval de 1936, el cual casi coincide por fechas con la exposición de Pablo Picasso. Se da la circunstancia de que el Gran Teatro del Liceo acogería un baile organizado por la Asociación de la Prensa a beneficio de los periodistas enfermos, de avanzada edad o en paro forzoso. Durante la celebración tuvo lugar un sorteo de productos fruto de la donación de diferentes empresas. Y entre ellos: "De la Casa Esteva S. A., Caspe, 21, un busto de María Antonieta, en bronce". ${ }^{44}$

\section{La III Exposición Internacional de Artes Decorativas de Monza de 1927}

Según hemos comentado anteriormente en la parte central del tríptico expositor aparece una inscripción que nos invita a pensar que este estuvo presente en la III Exposición Internacional de Artes Decorativas de Monza, en 1927 (Fig.12). El certamen, pretendía ser el escaparate donde mostrar: "Las manifestaciones del arte decorativo de absoluta modernidad y nobleza, de creación y ejecución" ${ }^{45}$. Dando protagonismo a las artes de la construcción, mobiliario urbano, elementos decorativos de la casa e interiores, ambiente infantil, arte sacro, artes del fuego, así como artes gráficas y didácticas, de los países allí representados.

En dicho certamen, que se inauguró el 31 de mayo de 1927 concurrieron un total de nueve estados: Italia, Suecia, Francia, Alemania, Hungría, Dinamarca, Suiza, U.R.R.S. y España. Cabe decir que estos cuatro últimos lo hacían por primera vez, ya que estuvieron ausentes en las anteriores ediciones de la muestra. Estas tuvieron lugar en 1925 donde concurrieron veintiún estados y en 1923, donde estuvieron presentes diecinueve. ${ }^{46}$ 


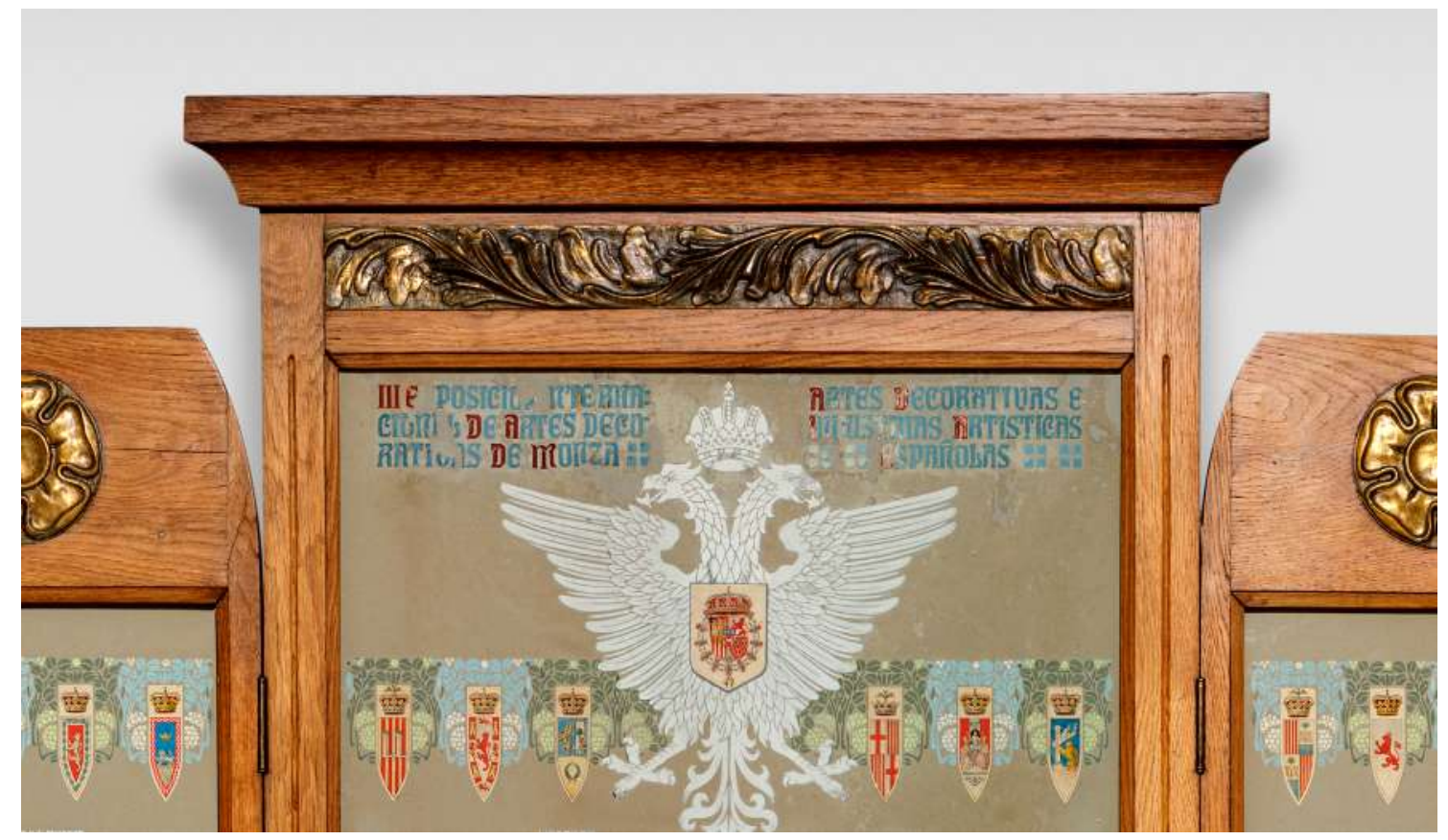

Fig. 12. La inscripción alusiva a la III Exposición Internacional de Artes Decorativas de Monza que aparece en la parte superior del tríptico debió añadirse en 1927, año en que tuvo lugar dicho certamen en la ciudad italiana. Foto: Estudio Rafael Vargas.

Gracias a la prensa de la época hemos podido saber que España estuvo presente en la III Exposición Internacional de Artes Decorativas de Monza con 89 expositores así como sus nombres, y que estos presentaron un total de 652 obras. Entre ellos no hemos encontrado el de Mateu Culell. ${ }^{47}$ El catálogo de la muestra, editado para la ocasión recoge detalladamente el nombre de los autores con obras expuestas, el título de las mismas o bien sus características, así como su ubicación en el recinto. Gracias al mismo sabemos que la Sección Española ocupaba las salas 122, 142, 143, 144 así como parte de una Galería situadas en la segunda planta del Palacio Real de Monza donde tuvo lugar el acontecimiento internacional. En la parte final del catálogo aparecen además relacionados todos los artistas participantes con obras expuestas y en ninguno de los casos aparece el nombre de Mateu Culell ni ninguna mención del tríptico expositor. Tenemos pues suficientes elementos de juicio para poner en duda que el autor catalán así como su obra llegasen a estar presentes en el certamen. Más bien pensamos que pudo haber una tímida intención de participar, por parte del proyectista industrial aunque esta posiblemente no llegó a materializarse.

Lo que sí sabemos con seguridad es que, entre el elenco de los 89 artistas o empresas artísticas con expositor propio en la muestra, en representación de España, entre muchos otros, se encontraban Adolfo Fargnoli, José $\mathrm{M}^{\mathrm{a}}$ Gol, Federico Marés, Luis Masriera, Masriera y Carreras, Juan José García, José Morell, Rafael Penagós, Antonio Calvache y Mariano Benlliure. ${ }^{48}$

El Fomento de las Artes Decorativas, como entidad no fue en esta ocasión receptivo a la invitación a participar en el certamen, contrariamente a lo sucedido en la Exposición Anglo-Latina de Londres de 1912. A pesar de ello encargó al pintor ceramista Josep Guardiola un estudio detallado sobre el contenido de 
la III Exposición Internacional de Artes Decorativas de Monza. Dicho trabajo debía incorporarse al archivo de la entidad barcelonesa. A tal efecto el artista se desplazó a Italia a principios de junio de 1927 para llevar a cabo su cometido, tal como recoge la prensa de la época. ${ }^{49}$

El estudio de Josep Guardiola se llevó a cabo y parece ser que fue publicado de forma íntegra en enero de 1928, una vez finalizado el certamen. ${ }^{50}$ Este trabajo más genérico de lo que hubiésemos deseado no llega a dar detalle del contenido de la Sección Española de la citada muestra circunstancia que no nos permite avanzar respecto a la cuestión planteada entorno de la supuesta presencia de Mateu Culell en el evento. ${ }^{51}$

En todo caso cabe afirmar que la formulación de los magníficos proyectos de decoración del dibujante industrial barcelonés así como el elegante mueble que los contiene, en 1927 no eran ya estandarte de modernidad, cuando triunfaba en Europa el Art Déco. Sobre todo, a partir de su entronización, en la Exposición de Artes Decorativas e Industrias Modernas de París de 1925. Tenemos diversos testimonios de trabajos presentados en Monza en 1927 que así lo ponen de manifiesto. Tal sería el caso del espejo decorado con una original tela de araña, diseño de Roberto Papini, exhibido en la sala 42 (Sala de la Sociedad Anónima M. Jesurum); del vitral I Cerbiatti proyectado por Ugo Ortona, construido en el taller muranés de Capellin e C. exhibido en la sala 45 (Sala de los maestros vidrieros muraneses Capellin e C.); el aparador proyectado por Alfio Fallica expuesto en la sala 53 (Sección romana) o bien la farmacia diseñada por Gigi Chessa exhibida en la sala 62 (Seccion piemontesa) en este caso propuestas que de alguna manera formaban parte de la Sección Italiana. Podemos también poner el ejemplo de las puertas-rejas proyectadas y ejecutadas por el artífice madrileño Juan José García, exhibidas en la sala 144 y que integraban la Sección Española. Todos estos testimonios, en este caso sí, impregnados de los nuevos aires de modernidad que corrían por la Europa más cosmopolita presentes también en la ciudad de Monza.

\section{Conclusión}

La localización y consulta de diversos documentos procedentes del archivo personal de Mateu Culell, cedidos por su hija Margarita, junto a numerosas obras de su progenitor, entre ellas el tríptico expositor, en 1960 y 1972 conservados en el Museo del Diseño de Barcelona ha sido de vital importancia para nuestro estudio. ${ }^{52}$ Contrariamente es difícil pensar que hubiésemos podido situar el mueble junto a su contenido en la Exposición Anglo-Latina de Londres de 1912. Y posiblemente tampoco hubiésemos cuestionado la presencia del mismo en la III Exposición Internacional de Artes Decorativas de Monza de 1927.

Estamos ante un caso excepcional donde nada es lo que parece. Los documentos conservados de la época nos aportan una valiosa información que nos permite situar el mueble ideado por el taller de Joan Esteva así como los proyectos decorativos de Mateu Culell que los contiene, en la Exposición Anglo-Latina de Londres de 1912. Aunque sorprendentemente la obra nos invita a pensar a partir de la inscripción que exhibe, que esta fue ideada para mostrarse en la III 
Exposición Internacional de Artes Decorativas de Monza en 1927. Lugar donde tenemos dudas razonables de que llegase jamás a exponerse el mueble.

No creemos que la presencia o ausencia del tríptico expositor en la III Exposición Internacional de Artes Decorativas de Monza de 1927 tenga especial trascendencia. Es de mayor relieve constatar que, el mueble fue seleccionado por Teresa-M. Sala para estar presente en la exposición: Barcelona 1900, de la cual fue comisaria y que tuvo lugar en el Van Gogh Museum de Amsterdam en 2007. Abandonando para la ocasión los espacios expositivos del Museo de las Artes Decorativas de Barcelona donde se hallaba expuesto desde el 2004. En la ciudad de los canales el tríptico expositor estuvo acompañado, entre otras, por obras de Antoni Gaudí, Ramon Casas o Pablo Picasso, todas ellas exponentes de la más brillante creatividad de la Barcelona de principios del siglo XX. ${ }^{53}$

Para finalizar cabe añadir, que el tríptico expositor desde el otoño del 2020 se exhibe en el Museo del Diseño de Barcelona en el marco de la muestra: Modernismo, hacia la cultura del diseño. Una exposición comisariada por Mireia Freixa y Pilar Vélez donde una vez más se pone en valor este movimiento cultural y artístico de raíz europeísta que con tanto arraigo floreció en la capital de Cataluña.

\section{NOTAS}

${ }^{1}$ Gran Exposición Anglo-Ibero-Americana, prospecto informativo. Fondo Mateu Culell. Museo del Diseño de Barcelona.

${ }^{2}$ La Vanguardia, Mayo 1, 1912, 8-9.

${ }^{3}$ Circular del Fomento de las Artes Decorativas. Fondo Mateu Culell. Museo del Diseño de Barcelona.

${ }^{4}$ Official Guide Latin-British Exhibition, London, 1912, 5-6.

${ }^{5}$ La Correspondencia de España, Mayo 8, 1912, 4.

${ }^{6}$ La Publicidad, Agosto 18, 1912, 1.

${ }^{7}$ Borrador de carta emitida por Mateu Culell, Mayo 23, 1912. Fondo Mateu Culell. Museo del Diseño de Barcelona.

${ }^{8}$ De acuerdo con el Libro de Actas del Fomento de las Artes Decorativas, depositado en el Centro de Documentación del Museo del Diseño, el 15 de marzo de 1903, en el momento de constituirse como entidad, Mateu Culell es nombrado vocal de la Junta Directiva, cargo que ocupará hasta el 22 de enero de 1905. El 27 de marzo de 1909 el proyectista industrial es elegido Vicesecretario cargo que ocupará hasta el 17 de octubre del mismo año.

${ }^{9}$ A modo de ejemplo podemos citar los cuatro proyectos decorativos que Mateu Culell presentó en la Exposición Nacional de Quito en 1909 que obtuvieron un Gran premio. Parece ser que el Presidente de la República de Ecuador quedó impresionado por la calidad de los mismos. Por mediación de Manuel María Coll Altabas, Comisario General de España en dicho certamen, Mateu Culell hizo donación de dichos proyectos al Gobierno de Ecuador. Fondo Mateu Culell. Museo del Diseño de Barcelona.

${ }^{10}$ Borrador del anexo a la carta emitida por Mateu Culell, Mayo 23, 1912. Fondo Mateu Culell. Museo del Diseño de Barcelona.

${ }^{11}$ Carta emitida por C. R. Chisman, Septiembre 12, 1912. Fondo Mateu Culell. Museo del Diseño de Barcelona. 
${ }^{12}$ No sabemos si el tríptico expositor se exhibió sobre una superficie plana, en ese caso entornados sus batientes laterales, o bien colgado en la pared, ya fuese con los batientes laterales extendidos o bien entornados.

${ }^{13}$ Agradecemos a la restauradora Èlia López sus explicaciones sobre el proceso de elaboración y ejecución de los proyectos decorativos de Mateu Culell contenidos en el tríptico expositor.

${ }^{14}$ La Exposición Nacional de Quito se inauguró el 10 de agosto de 1909 y finalizó el 31 de enero de 1910. De acuerdo con el Catálogo General de los Premios conferidos por el Jurado de la Exposición a los concurrentes al certamen nacional inaugurado en la capital de la República del Ecuador el 10 de agosto de 1909 con motivo del centenario de la independencia sud-americana proclamada en Quito el 10 de agosto de 1809, p. 7, Mateu Culell presentó cuatro proyectos de decoración, por los cuales obtuvo un Gran premio. No tenemos noticia que recibiera medalla de oro, contrariamente a la afirmación que se hace en la inscripción que aparece en el tríptico expositor.

${ }^{15}$ Se corresponden con la Exposición Nacional de Bellas Artes, 1901; Exposición Internacional de Atenas, 1903; Exposición Hispano-Francesa de Zaragoza, 1908; Exposición Internacional de Rotterdam, 1909; Exposición Universal de Bruselas, 1910; Exposición Nacional de Quito, 1910; Exposición Internacional del Centenario, 1910; Exposición Internacional de Artes y Manufacturas, 1910.

${ }^{16}$ Agradecemos a Dani Tutusaus, técnico de jardinería del Instituto Municipal de Parques y Jardines del Ayuntamiento de Barcelona la identificación de esta especie vegetal, en el proyecto decorativo.

${ }^{17}$ El mueble fue restaurado en la primavera del 2020 por Lourdes Domedel, Voravit Roonthiva y David Silvestre, bajo la coordinación de la conservadora-restauradora del Museo del Diseño de Barcelona, Silvia Armentia.

${ }^{18}$ Agradecemos a Jordi Carreras, historiador del arte, algunas precisiones entorno a la iconografía del tríptico expositor.

${ }^{19}$ L'Atlàntida 133, Marzo 31, 1900, 7.

${ }^{20}$ Se da la circunstancia de que Joan Esteva el 17 de mayo de 1912 fue nombrado Vicepresidente del Fomento de las Artes Decorativas, cargo que ostentará hasta el 25 de octubre de 1914, de acuerdo con el Libro de Actas de la entidad, depositado en el Centro de Documentación del Museo del Diseño. Mateu Culell y Joan Esteva dado el estrecho vínculo que mantenían con el Fomento de las Artes Decorativas es evidente que debieron de conocerse y tratarse personalmente.

${ }^{21}$ AHPB, notario Ricardo Permanyer Ayats, 22-6-1900, protocolo n ${ }^{\circ}$ 610, pp. 2875-2880.

${ }^{22}$ Cabe tener en cuenta que la calle Cardenal Casañas anteriormente llevaba el nombre de Riera del Pino, donde a veces encontramos referenciado el establecimiento comercial, tratándose pues de una misma ubicación.

${ }^{23}$ La Vanguardia, Abril 17, 1902, 2.

${ }^{24}$ Catalunya 30 (junio de 1904): 110.

${ }^{25}$ AHPB, notario Ricardo Permanyer Ayats, 19-4-1905, protocolo no 325, pp. 1311-1313.

${ }^{26}$ La calle Universidad, desde 1916 es conocida oficialmente con el nombre del compositor Enrique Granados.

${ }^{27}$ AHPB, notario Miguel Martí Beya, 18-7-1905, protocolo n ${ }^{0} 510$, p. 3156-3163.

${ }^{28}$ La Vanguardia, Noviembre 30, 1905, 2.

${ }^{29}$ El Magisterio Español. Periódico de Instrucción Pública 3010, Julio 4, 1906, 12.

${ }^{30}$ La Vanguardia, Agosto 30, 1907, 8-9.

${ }^{31}$ AHCB, notario Ricardo Permanyer Ayats, 20-1-1908, protocolo n ${ }^{\circ} 47$, p. 150-167.

32 Agradecemos a Santi Barjau, del Departamento de Gráficos del Archivo Histórico de la Ciudad de Barcelona la identificación de l'autoria del logo del establecimiento comercial de Joan Esteva. 
${ }^{33}$ Antonio Navarrete Orcera es filólogo y especialista en la antigüedad clásica. Agradecemos sus acertadas aportaciones.

${ }^{34}$ La Vanguardia, Noviembre 27, 1912, 5.

${ }^{35}$ La Vanguardia, Junio 24, 1913, 3.

${ }^{36}$ La noticia recoge exhaustivamente de forma alfabética el nombre de las mujeres representadas con sus obras en la exposición, todas ellas alumnas de la Academia Martí. La Vanguardia, 8-12-1913, p.4.

${ }^{37}$ La Vanguardia, Noviembre 1, 1921, 10.

${ }^{38}$ Exposición Internacional del Mueble y Decoración de Interiores. Album resumen, A. Torramadé, Barcelona, 1924.

${ }^{39}$ La Vanguardia, Enero 30, 1924, 8.

${ }^{40}$ Josep Capsir, "La alfombra de Tomàs Aymat y el boudoir de la Reina en el Palau de Pedralbes en 1924," Art Déco. Història, materials i tècniques, (Barcelona: Associació per a l'Estudi del Moble, Ajuntament de Barcelona, 2018), 65-74.

${ }^{41}$ En el 2011 desde el Museo de las Artes Decorativas de Barcelona, situado en el Palacio de Pedralbes se impulsó la recuperación de la decoración original de los dormitorios reales, de Alfonso XIII y Victoria Eugenia, en vistas de abrirlos al público. Algunos de los muebles que originalmente ornamentaron dichos espacios, acondicionados entorno 1924, se encontraban dispersos por diversas estancias del regio edificio. Otros ni tan siquiera pudieron ser localizados. La mesita costurero se hallaba en el dormitorio de la Reina. Aunque originalmente nunca estuvo allí, se consideró oportuno dejarla en aquel espacio, ya que la decoración de la estancia estaba inspirada en el estilo Luis XVI, justamente el mismo que evocaba dicho mueble. Y se pudo documentar su antigua presencia en la salita de estar de la Reina. Por tanto, era un mueble vinculado a las estancias de uso personal de Victoria Eugenia. El Museo de las Artes Decorativas de Barcelona cerró sus puertas en 2012, debido al traslado de sus colecciones al nuevo edificio de la Plaza de las Glorias.

${ }^{42}$ La mesita costurero no tenía ninguna inscripción ni placa identificativa del taller que la produjo.

${ }^{43}$ AMCB, Sección de Hacienda, Negociado de Presupuestos. Expediente relativo a las facturas pendientes de pago y acuerdos para satisfacerlas, del Palacio de Pedralbes, $\mathrm{n}^{\circ} 1.557$.

${ }^{44}$ La Vanguardia, Febrero 15, 1936, 9.

${ }^{45}$ Las Noticias, Febrero 20, 1927, 1.

${ }^{46}$ Guido Marangoni, La III Mostra Internazionale delle Arti Decorative Monza 1927. Noticierilievi-risultati (Bérgamo: Instituto Italiano d'Arti Grafiche, 1927). Agradecemos las gestiones realizadas por M. José Balcells del Centro de Documentación del Museo del Diseño para la localización y posible consulta del libro.

${ }^{47}$ El Sol, Junio 2, 1927, 5.

${ }^{48}$ Catalogo ufficiale della III Mostra Internazionale delle Arti Decorative maggio ottobre 1927 Villa Reale Monza (Milán: Casa Editrice Ceschina, 1927).

${ }^{49}$ El Diluvio, Junio 3, 1927, 13.

${ }^{50}$ Josep Guardiola, "Estudi-Crítica d'orientació a l'exposició de l'art decoratiu a Monza," Arts $i$ Bells Oficis (Enero 1928), 49-61.

${ }^{51}$ Teníamos ciertas expectativas respecto a la presencia de documentación escrita y fotográfica generada por la visita de Josep Guardiola en 1927 a la III Exposición Internacional de Artes Decorativas de Monza, en el Archivo del Fomento de las Artes Decorativas, depositado en el Centro de Documentación del Museo del Diseño de Barcelona. Todo parece indicar que el encargo de dicha entidad al artista quedó plasmado en su totalidad en el artículo recogido en la revista Arts i Bells Oficis sin que exista localizado a día de hoy un fondo documental que complete su contenido. Agradecemos la revisión del inventario del Archivo del Fomento de las Artes Decorativas realizado, por Montse Peris y Núria Gil. 
${ }^{52}$ El tríptico expositor, protagonista de nuestro trabajo, llegó en 1960 al Museo de las Artes Decorativas de Barcelona, producto de la donación de Margarita Culell, hija del proyectista industrial.

${ }^{53}$ Nuestra tarea profesional desarrollada en el Museo de las Artes Decorativas de Barcelona durante el periodo 1994-2014 nos permitió ser testigos en septiembre del 2007 tanto del embalaje del tríptico expositor en Barcelona, así como del desembalaje en Amsterdam y su colocación en el espacio expositivo del Van Gogh Museum donde tuvo lugar la muestra Barcelona 1900. También asistimos al terminar la exposición en enero del 2008 a su embalaje en Amsterdam así como su desembalaje en Barcelona e instalación de nuevo en los espacios expositivos del Museo de las Artes Decorativas. 